\title{
Realidad Lírica Peruana
}

SE dice una verdad rotunda - por tal razón siempre evadida por los "críticos" - cuando se afirma que la actitud literaria peruana, en cualquiera de sus anteriores etapas, no correspondió en ningún sentido a nuestras realidades. "Fué una actitud de cultura, no una actitud de espíritu", tal, como para toda América, lo asevera Juan Marinello.

El Perí colonial y el Perú republicano de la primera centuria, mantuvieron fieles los oídos domésticos a los mensajes literarios que dictaba, variando entonaciones y señales, la dictadura artística de Europa. Situación original y absurda, instaurada en todo el continente, no era por cierto sino el cordón umbilical con que seguíamos atados al patronazgo occidental. Perfectas colonias de ultramar, nada faltaba para el vasallaje, ya que presidiéndolo, tal como ahora, alzaba su vigencia decisiva el tutelaje económico. Europa timoneaba los gustos, las rutas y los avances literarios, en la misma forma omnipotente y veleidosa con que hacía oscilar el valor de la moneda y mantenía las riendas comerciales de nuestros países.

Pero esta suerte de dictadura artística, es deber reconocerlo, no era obra deliberada de los occidentales. Europa creaba direcciones estéticas y mudaba caminos en el Arte respondiendo a exigencias ineludibles de su evolución histórica. Cada escuela literaria, cualquier tendencia artística, toda remuda de ideales, nacían a la acción en perfecta consonancia con las realidades políticas, económicas y sociales. Revoluciones artísticas, pues, hechas como a la medida para la realidad que integraban y enfrentaban. Y América las hacía suyas porque sí, al estilo de las modas, brindando el mandato gratuito de su complaciente coloniaje a los cenáculos europeos. La irrespon- 
sable actitud no podía engendrar sino este hecho harto conocido: mientras las expresiones literarias europeas señoreaban en su Continente, como frutos de un largo proceso económico y social, en América venían a cumplir el papel de flores de invernadero, celosamente cuidadas por media docena de intelectuales. Hecho tan natural como ésta su consecuencia: en más de una ocasión los literatos americanos fueron cultivadores trasnochados de escuelas ya caducas o de movimientos literarios plenamente liquidados en Europa.

Los artistas de talla mayor que exhibe América en tales épocas, no son ni pueden ser representantes continentales de tal o cual revolución artística nacida en otras latitudes. Fueron siempre una especie de Robinsones, creadores de su propio mundo, con temperamentos cuya expresión coincidió, en veces, con las directivas vigentes en Europa. Salvo, claro está, los evadidos de América, algunos de los que llegaron a gonfalonear nuevas escuelas, por paralelos y en idiomas extraños, con fruto glorioso e indiscutible aunque en franca condición de descastados.

París, más que otros centros europeos - tornado meridiano cultural- casi siempre exportó sus mandatos literarios a través de España, cuyas aduanas - como aquellas de la Casa de Contratación de Sevilla- demoraban el reembarque y dejaron zarpar las galeras con mercaderías trasnochadas en más de una ocasión. América no discutía el envío. $\mathrm{Y}$ aceptaba las corrientes de ultramar con la misma sumisión con que los indios recibían las imposiciones del comercio colonial; con la diferencia de que unos - los literatos- aceptaban con deliberada complacencia los abalorios forasteros y las modas inútiles, en tanto que los otros - los indios- se hacían de las navajas, los naipes, los espejos y las podridas mercancías, bajo el látigo de encomenderos y corregidores.

En realidad, ambos se hacían de desechos. $Y$ una producción literaria amasada con desechos - así fuera con directivas de primera mano ajenas a su ámbito - nada valedero podía forjar para nosotros. De ahí que: ¿cuál es la alta contribución de América al romanticismo, al naturalismo, al parnasianismo y demás movimientos que agitaron los espíritus de Europa, a la par que sus revoluciones politicas, sociales y económicas? Ninguna. No hay obra cumbre capaz de alinearse al lado de las grandes obras europeas. Lógicamente, no pudo haberla. Las obras meritorias nacidas en América, particu- 
larmente del tipo romántico y modernista, no han sido producto sino de la aptitud de creadores aislados cuya expresión adoptó, naturalmente, el cauce demandado por su espíritu. En poesía, sobre todo, se tradujo el temperamento de cada creador, aflorando libremente con cualquiera de esas disposiciones - hipopsíquica, hiperpsíquica, mesopsíquica- - en que divide Ramón Pérez de Ayala las aptitudes innatas del poeta.

La actitud subordinada fué común a todo el Continente. En ningún país tuvo la literatura la vitalidad y la trascendencia propias de las literaturas que nacen y se afirman en íntima consonancia con sus propias realidades. El Perú, como los demás, vivió de prestado, siguiendo con dócil afán las vicisitudes de la literatura occidental. En tan larga época huérfana de modos propios no puede confortarnos, sino en parte, la insurgencia inusitada de algunas figuras que agitan el panorama cultural, para enseñarnos las primeras posiciones verticales del espíritu - base de toda liberación - y cuyas voces con perdurable resonancia sostienen hasta hoy el aliento emancipador de nuestra literatura. Baste citar a don Manuel González-Prada, quien con obra y ejemplo nos enseñó a ser hombres, porque ni eso sabíamos, según la firme expresión de Alberto Hidalgo.

Esta situación de apego y servidumbre a todas las señales literarias de afuera abarca todo el período colonial y persiste en el primer siglo de la República. Su liquidación sólo había de empezar cuando la conflagración del año 14 -de la que fué partícipe América en uno $\mathfrak{u}$ otro sentido- desparrama sus consecuencias revolucionarias en el mundo, tras el primer acto de una tragedia que empalma su encendida vigencia a la hora presente. Allí, en el período de la postguerra, hay que buscar las raíces que amparan el gesto propio ensayado por la literatura continental. $\mathrm{Y}$ en tal período, fecundo y contradictorio, encuéntrase el origen de la actual poesía peruana, materia de mi ensayo.

ANTECEDENTES Y PRECURSORES

Hacia 1915 empieza a bambolearse la especie de Bastilla literaria instaurada en Lima desde la Colonia. Usando y abusando de un centralismo de lejana tradición, la capital monopoliza obras, direc- 
ción y prestigio de la cultura del Perú. De sus cenáculos salían las directivas y las normas, los rumbos y las consagraciones literarias. $\mathrm{Ni}$ la voz ni la acción de las provincias se hacían presentes. Mensajes provincianos que arriban, de tarde en tarde, languidecen por falta de ímpetu o se desnaturalizan al pasar por las aduanas de un ambiente literario hostil y encoyundado a las brújulas literarias europeas.

No olvido, por cierto, la rebeldía del "cholo" Meza y la talla serrana de su prosa, sin acústica posible en un medio de aire enrarecido, donde los mejores impulsos torcían a la negación de sus fueros, mitad por las urgencias del pan regateado y otro tanto por la evasión a los planos viciosos y esnobistas del decadentismo forastero. A la larga, era la única evasión posible aunque estéril, de un mundo hostil y lleno de prejuicios; a la manera de los románticos franceses, que en pugna arrebatada y también inofensiva, desdeñaban al burgués y se fugaban a latitudes ideales. (Aquí como allá, con los pueriles intentos de "epatar" : un literato paseando con zapatos de dos colores; Teófilo Gautier luciendo su clásico chaleco rojo). Junto al cholo Meza hay que recardar a otro alto temperamento provinciano: Abraham Valdelomar. Talentoso y sibarita, muere sin acabar de desprender los ojos de Europa y de su cielo colónida, pero vale su ejemplo de literato de provincia, impuesto sin antecedentes sociales o de fortuna, por virtud exclusiva de talento, aunque para imponerlo haya tenido que usar toda una estrategia de talantes y posturas.

De pronto, con un empuje inesperado, insurgen las provincias. $Y$ la región -como lo registra Alberto Ureta - cobra un valor desconocido y hasta una beligerancia inusitada en la literatura peruana.

El movimiento nace, se estructura y se expande desde dos ciudades del Perú: Trujillo y Arequipa. Alberto Hidalgo comanda el grupo del Sur que irrumpe con más acentuada rebeldía y ataca con menos misericordia al feudo literario limeño. Posteriormente ha de darle el golpe de gracia (Muertos, heridos y contusos, 1920) y en compañía de Alberto Guillén (La linterna de Diógenes, 1921). Los dos colocan, también, los primeros impactos sobre el decadente Modernismo y lanzan la modulación inicial de la poesía nueva: Guillén, con lastre romántico, todavía; Hidalgo, con entonación más decidida, a impulsos del aliento marinettiano. No cuadraba mejor título a la revista que sirvió de expresión a ese grupo: Anunciación. De anunciación era en efecto su voz. Anunciación del nuevo orden 
poético que a poco se incorporaría definitivamente a nuestra literatura.

Hasta alli, hasta el grupo del Sur, y más propiamente en Hidalgo, su gonfalonero, hay que ir a rastrear el impulso de la faena revolucionaria que barrió con los módulos poéticos imperantes y afloró en obra madura ya nó en ellos, sino al otro extremo del Perú, en Trujillo, con César Abraham Vallejo (Trilce, 1922, publicado en Lima).

Si ese es el camino -el del Sur y el grupo de Hidalgo- para encontrar el impulso revolucionario, hay que voltear la vista al Norte, a Trujillo, para toparnos con el primer encaramiento a la tierra, a 1o nuestro, que es como decir el descubrimiento de la primera actitud peruana. La dirección parte de un grupo donde alternan Antenor Orrego, Alcides Spelucín, César Abraham Vallejo, José Eulogio Garrido, y otros escritores y poetas de una generación que se enfrenta a su ámbito. Le corresponde a Vallejo el primer esfuerzo organizado al plasmar poéticamente la inquietud aquella en Los heraldos negros (1918). Libro es éste de neta raíz romántica por su sinceridad y el primer inventario lírico de la temática andina conjugado con el nuevo espiritu. En la tesis que Vallejo presentó para el bachillerato en Letras (Universidad de Trujillo, 1915), pedía a nuestros poetas usar la sinceridad de los románticos para liquidar su condición de vasallos y enfrentarse con voz propia a las tareas de su vocación lírica. Consigno aquí sus frases: "Hoy en el Perú, desgraciadamente, no hay ya el entusiasmo de otros tiempos por el romanticismo; y digo desgraciadamente, porque siendo todo sinceridad en esta Escuela, es de lamentar que ahora nuestros poetas olviden esta gran cualidad que debe tener todo buen artista. Dados demasiado a la imitación, hoy más que nunca se despliega la tendencia desenfrenada por seguir en literatura el camino de fuera. Necesitamos proclamar nuestra autonomía literaria".

Sirvió de vehículo de expresión para el grupo norteño la revista Perú (posteriormente aparecería Norte, dirigida por Orrego), cuyo sólo nombre está dando ya la tónica de la inquietud literaria. En ella se revela el nombre de otro poeta: Alcides Spelucin, quien evidenciaría la conquista de nuevos avances estéticos en su obra primigenia, El libro de la nave dorada, publicada destiempo en 1926. 
La actitud de las provincias no queda allí. Vallejo e Hidalgo vienen a Lima y allí dan la batalla decisiva. En vano pontífices literarios tratan obstinadamente de cerrarles el paso. Entre ellos el pontífice de "Correo Franco", en la revista Variedades, desahucia la poesía de Hidalgo y le sugiere paternalmente a Vallejo que cambie el ejercicicio poético por la siembra de zapallos o papas. (Vallejo aparecía caricaturizado, ilustrando esa crítica, tendido sobre los rieles de una línea férrea, sirviéndole de almohada una melena colosal.) Era en vano todo lo desplegado por la cándida defensa de los reductos literarios acorralados. Llegaba el principio del fin. Venciendo una etapa miserable y dolorosa, Vallejo publica Trilce. La audacia de este libro, renovado en forma y fondo, trastornando leyes y principios consagrados, con calidades de cosa primordial, recién nacida, provoca una enconada reacción de hostilidad en el ambiente. Acertó Bergamín al decirlo en el prólogo de la segunda edición. Pero la voz ruda, tajante y decisiva había sonado y no había poder capaz de acallarla. Por lo demás, a pesar de la indiferencia que substituyó a la hostilidad inicial por su aparición, Trilce se ha vengado con creces al conquistar consagración unánime y al convertir en admiradores suyos a los más recalcitrantes detractores de la primera hora.

Hidalgo, entretanto, había viajado a Buenos Aires tras imponer su libro Muertos, heridos y contusos, y, superando la nota vanguardista, publicó dos nuevas obras: Tu libro y Química del espiritu (Buenos Aires, 1926).

Es así como empieza a perfilarse la poesía peruana inaugurando su presencia en la literatura merced a la voz de las provincias. Posteriormente veremos que el comando adquirido por ellas, con esta. inesperada insurgencia en la escena literaria del Perú, lo siguen. manteniendo hasta hoy.

\section{LA ETAPA DE TRANSICION}

Por aquellos años Europa comenzaba a desbordar todas las vastas consecuencias revolucionarias de la guerra del 14. América, sacudida profundamente en sus raíces económicas, abrió los ojos: ante el panorama inédito que se le presentaba, nutrido de sugestiones y perspectivas en todos los órdenes de la vida. En trance desconcertado, anárquico, inconforme, los hombres de postguerra comienzan a 
tantear càuces, a barajar mitos, a ensayar expresiones. En la peripecia histórica de aquella búsqueda es bien cierto que enfrentaban, como lo dijera José Carlos Mariátegui, el alma desencantada dicha por Ortega y Gasset al alma encantada de que hablaba Romain Rolland. En términos claros, revolución y decadencia, coexistentes y en pugna, aflorando en la crisis inexorable que le deparaba esta etapa de la civilización capitalista. Etapa postrera, decadente, fielmente reflejada - lo dijo también Mariátegui- en la atomización, en la disolución de su Arte. El Arte pierde su unidad esencial; cada uno de sus principios y elementos reivindica su autonomía. De la desintegración de ese arte surge el aluvión de ismos, cuyo imperio efímero, contradictorio, iconoclasta, instauraría el período más anárquico, y al mismo tiempo más esperanzado, en la historia del Arte: el de la vanguardia.

En el Perú toma carta de ciudadanía el movimiento vanguardista al mismo tiempo que los primeros brotes de la prédica social. $Y$ la lírica de vanguardia eliminó tácitamente a todos los poetas consagrados del anterior período, siendo conjugada en su totalidad por voces nuevas. A José Carlos Mariátegui (conductor de Amauta, luego, en 1928) se le debe el aliento más cordial y avizor en esta etapa, secundado de lejos por Alberto Hidalgo, y en Lima por inquietos animadores a cuya cabeza se puede citar a Luis Alberto Sánchez, Jorge Basadre y J. Guillermo Guevara, director de Sierra.

Como información ilustrativa registro a continuación nombres y revistas, surgidos a impulsos de la nueva inquietud, que jugaron un activo papel estimulando a realizadores y realizaciones literarias vanguardistas. Antenor Orrego y El Norte (Trujillo); los hermanos Peralta y José Z. Portugal, en Puno, con las editoriales Titikaka y Kuntur, respectivamente; Nicanor de la Fuente (Bocina, Chiclayo); Manuel Gallegos Sans (La Aldea) y Francisco Mostajo (Escocia), en Arequipa; en Lima: José Carlos Mariátegui (Amanta), Armando Bazán (Poliedro), Jorge Basadre y Adalberto Varallanos (Jarana), Serafín del Mar y Magda Portal (Hangar), Blanca Luz Brum (Guerrilla), Carlos Oquendo (Hurra) y Federico Bolaños (Flechas), y merced al ánimo de César Barrio abrió sus columnas al nuevo movimiento - sin persistir - la revista conservadora $\mathrm{Mer}$ curio Peruano.

Entre la multitud de nombres salidos a la escena literaria cito estos autores como de intención más significativa : César Alfredo Miró 
(Cantos del arado y las hélices), Juan José Lora (Lydia), Serafín del Mar (Radiogramas del Pacifico), Magda Portal (Una esperanza y el mar), Emilio Armaza (Falo), Enrique Peña (El aroma en la sombra), Mario Chávez (Coca), Juan Luis Velásquez (De perfil y de frente), Luis Rodríguez (Himno al Ande), Alberto Mostajo (Cosmos y Canción infinita), N. Chávez Aliaga (Parábolas del Ande). De fuera nos llega la persistente inquietud de Alberto Hidalgo con Descripción del cielo, Indice de la poesía hispanoamericana y Antología de Vanguardia, y el libro de Enrique Bustamante y Ballivián, Antipoemas.

Cuando la estridencia alzaba su coro más encendido, suenan las primeras voces pidiendo serenidad para delimitar plenamente el contenido y las aspiraciones de la nueva poesía. Era una invitación de retorno a lo que de imperecedero tiene el Arte; ir hacia sus formas eternas para vaciar la nueva sensibilidad. Que era lo que importaba y lo valedero. Urgía iniciar el inventario de las nuevas conquistas estéticas y marcar el catuce formal por donde debían avanzar, tal como ya se intentaba en México y en Buenos Aires. $Y$ en la faena, oyendo la voz admonitiva de Mariátegui, quien, para creer en una revolución artística, exigía que a una nueva técnica correspondiera plenamente un nuevo espiritu.

Frente a ese reclamo el panoramá confuso de la vanguardia, poblado de voces dispares, de impulsos contradictorios, negado y afirmado, se aclara lentamente para mostrarnos el saldo definitivo que nos deja en herencia. Esta fué la herencia: destierro de la rima, libertad métrica del verso, imperio de la metáfora, redescubrimiento de la palabra. El más significativo saldo, sin embargo, era el nuevo espíritu.

Ese nuevo espíritu no podía resolverse sino en estos hechos: la cancelación del enyugamiento a los patrones literarios europeos, posesión de nuestro ámbito geográfico, hallazgo de la tragedia humana del peruano y la conciencia recién comprendida del papel social del Arte, con deberes de ineludible ejercicio en la lucha reivindicadora del mestizo.

Las provincias se identifican de inmediato, acentuando sus primeros impulsos, con la técnica nueva y con el nuevo espíritu. La capital y sus círculos poéticos desoyen lạ gran voz del nuevo espíritu y eluden la obediencia a sus mandatos -obediencia que implica 
una cabal definición del hombre como artista y ciudadano- para recluirse en los claustros del "purismo", donde no habían de cumplir más tarea que el culto intrascedente a los aspectos siempre externos y superficiales de la técnica.

Es la hora en que de nuevo, una vez más, las provincias y Lima se ponen frente a frente.

Naciendo en las provincias, siguiendo la tónica peruana que inició el grupo literario del Norte a la par que las señales de la nueva técnica poética puestas por Vallejo, Hidalgo y Guillén, emerge todo un coro de voces vigorosas con el mensaje inicial de un movimiento netamente peruano: el regionalismo poético. Entre los de más decidida entonación saltan a la arena poética Alejandro Peralta ( $E l$ Ande, Puno, 1926); dos años después Guillermo Mercado (Un chullo de poemas, Arequipa, 1928), y el mismo año Anaximandro Vega, Cristóbal Meza, Luis de Rodrigo ( $\mathrm{y}$ otros poetas agrupados en Sierra, mensuario dirigido por J. G. Guevara) y Alberto Cuentas (Rumores del Titicaca, Puno, 1929). Junto a Peralta, en la misma ciudad, el mismo año, sale a luz Emilio Armaza (Falo, Puno, 1926).

Mensaje inicial el que traían he dicho. $Y$ es cierto. No sólo porque conjugaban con mayor pericia el acento peruano, sino porque ensayaban aún el paso decidido con que se desplazarían en el futuro. Habían descubierto su posición frente al paisaje propio, se sentían mejor plantados en el ámbito vernáculo y el torrente de la sangre comenzaba a sentir los latidos de un impaciente tropel de impulsos y mandatos con que la tierra amanecía, por fin, a dirigir trajines y caminos. Pero aún era, reconozcámoslo, la mera actitud. Que lo verifiquen, si no, los versos de Peralta y Vega. De la actitud se pasaría luego, y muy luego, a la aptitud madura y desenvuelta hasta identificarse con el ámbito y la emoción del hombre que cumple allí, urgido de sueños y desastres, su peripecia social y humana.

Los poetas limeños, entre tanto, tomaron posiciones en actitud diametralmente opuesta. Cargan en andas el "disparate poético" del vanguardismo y lo instalan en una isla poética, hasta la cual no habían de llegar, lógicamente, ni los requerimientos del paisaje ni los reclamos, cada vez más encendidos, del peruano y del drama social que vive. La tal isla se convierte en una suerte de capilla de la poesía pura o purista, como les cuadra a sus animadores. 
Las dos tendencias, paralelamente surgidas, apresuran el paso y se desenvuelven hacia el perfil definitivo, a partir del año 30 . A tal determinación la empujan, con no poca fuerza, las derivaciones del descalabro dictatorial de Leguía. Pero con más urgencia condicionan esa delimitación y plantean el duelo los frutos del mensaje social de José Carlos Mariátegui, la lucha polémica en defensa del indio, empeñadas por él y Zulen, y, sobre todo y con más decisiva inspiración, voz y acción de los primeros gonfaloneros de la izquierda peruana. Haya de la Torre, Luis Alberto Sánchez y Luciano Castillo.

Hacia 1931 el Perú siente el primer impulso renovador de su historia republicana. Es que advienen organizadas las nuevas fuerzas ideológicas de izquierda y se plantea la lucha con la derecha, que cierra desesperadamente sus cuadros para resistir el choque. Es harto conocido el desenlace para exhibirlo aquí. Pero la contienda enardecida, sacudiendo con su resonancia todos los ámbitos peruanos y comprometiendo en la lucha a todos los espíritus, crea el estado de conciencia definitivo que es norma de conducta y trayectoria del peruano de hoy. La conmoción política y la admonición social sacan a luz un nuevo clima como aclaran horizontes y desdoblan rutas flamantes para el desenvolvimiento de la vida y la cultura en general.

Es entonces cuando el regionalismo poético acentúa su tónica, precisa sus contornos y yergue su maciza personalidad. La contraparte lírica - también podíamos decir ideológica- define sus posiciones y desdé las trincheras del llamado purismo se hace presente en la escena literaria. No a lidiar, claro está, sino a exhibir, aristocráticamente, según expresión de su apologista, el ejercicio de un purismo "donde se utilizan elementos literarios de la más selecta gama estética" (Estuardo Núñez, Panorama actual de la poesía peruana, p. 44, 1, 4, Lima, 1938). Tal purismo vamos a registrarlo a continuación, no porque tenga representación alguna como movimiento expresivo de la lírica peruana, sino porque sirve para darles relieve y destacar los perfiles del regionalismo poético, capaz de ser denominado, también, peruanismo lírico. 


\section{EL PURISMO}

Arrancando de José María Eguren, pasando por Oquendo de Amat, el purismo se refugia, finalmente, en el grupo que reconoce como animador a Martín Adán, y cuyos afiliados siguen dos huellas fraternas: la de Paul Valéry (Ennique Peña, José Hernández y Alvarado Sánchez) y la de André Breton (Emilio Wesphalen y Xavier Abril). Para definir esta tendencia más vale oír a quien ya regala a sus cultivadores con la inmortalidad literaria: "Son atributos del purismo la ruptura del correlato con la realidad inmediata, nuevas formas de selección y buen gusto, segregación de prosaísmos"; es "Io puro en el sentido más normal del adjetivo", "el sentido virginal e inexhausto del objetivo puro aplicado al fenómeno poético"; "carencia de toda conexión intelectualista". "Como la realidad es fea por definición, y como la belleza no existe sino en lo que no es real, los puristas vuélvense a ese reino interior donde campean las imágenes”. O sea: evasión del mundo, aristocratización del vocablo, deshumanización del verso, exploración metafísica, negación conceptual, omnipotencia de lo inconsciente.

Definido el purismo voy a puntualizar la paradoja que encontró Huberto de Fabureau, en los ensayos teóricos y prácticos de Paul Valéry, padre de la poesía pura. La paradoja es ésta : partiendo del fetichismo de la poesía pura, según el cual poesía no sería otra cosa que un mero juego de sonidos, despojados de todo concepto y contenido, llegaríamos forzosamente a la conclusión de que la poesía pura no es ni más ni menos que el silencio. Si las palabras comprometen irremediablemente la poesía que tratan de expresar, el poeta preferirá callarse. Así, pues, cuanto más poeta se sienta el que como tal escribe, más fácilmente resistirá a la tentación de hacer versos, porque cuanto más poeta se sea, en mayor horror se tendrán aquellas impurezas, esos prosaísmos que toda expresión poética arrastra fatalmente consigo: ideas, sentimientos, imágenes.

De este modo los puristas quedarían sin instrumento de expresión. Ya Goethe - declarándose impotente para arrancar todos los secretos de su lengua alemana- actualizaba la verdad eterna de que la poesía es el fruto de la dramática lucha del poeta con la expresión. $\mathrm{Y}$ ateniéndose a las realidades tangibles y positivas del oficio de poeta, y a los resultados evidentes de su ejercicio, tomando como 
base la materia específica con que trabaja, "la poesía puede llana y simplemente definirse como el arte del lenguaje". Lenguaje humano con que los puristas no pueden cumplir la tarea, por demás insensata, de captar la esencia metafísica de la poesía. Alguien dijo que la poesía es "la adivinación de lo espiritual en lo sensible, expresándose por mediación de lo sensible". La belleza - cito a Miguel de Montoliu- para ser percibida o adivinada por nuestros ojos, por nuestros oidos, por nuestra sensibilidad, necesita del vehículo de la impureza, asi como el sol para irradiar su luz en el planeta necesita de la atmósfera. Con éter solo no se concibe ni luz ni poesía hechas para el hombre. Lo contrario es olvidar, llevados por la tenaz quimera de la poesía pura, la conformación de nuestra arquitectura espiritual. Para el espíritu del hombre jamás alcanzará vigencia una poesía de productos esterilizados de todo jugo humano, aconceptuales y metafísicos, fraguados a espaldas de su drama. El organismo espiritual del hombre no admite, no quiere ni puede asimilar los frutos desabridos de esta monstruosa deshumanización del Arte, cuyo culto, en realidad, no es más que un nuevo vicio solitario, como lo calificara, fulminándolo, Rufino Blanco-Fombona.

Pero esa su filiación negativa de vicio solitario ayuda a comprender un hecho: con los puristas retorna al Perú una posición artística que parecía definitivamente cancelada: la del arte por el arte. Actualización de algo tan absurdo como contradictorio con nuestra realidad, en igual forma que lo es aquel vano esfuerzo de angelización en que se resuelve toda la aspiración de la poesía purista. Anduvo desacertado por lo visto Máximo Du Camp -el contemporáneo de Lamartine y de Dumas, hijo- cuando rotundamente afirmó que "la escuela del arte por el arte no volverá a encontrar su época".

Apasionada preocupación por los aspectos externos y siempre superficiales de la técnica (clave de indiferencia social); obstinado desdén por las realidades cuotidianas; exploración metafísica e "investigación de lo inútil" (Flaubert); imperio del yo introvertido como única realidad - ¿o irrealidad?-; decantación verbal y alquimia de motivos para versos aconceptuales, sin contenido, con mero paramento ("La poesía no demuestra nada, la belleza del verso sólo depende de su música" - Teófilo Gautier); producción lírica para "iniciados" ("Nuestros libros no son para todos, van para los 
selectos" - Carta de Flaubert). Tales características del purismo, salvando pequeños distingos, ¿ no son las mismas que informaron y definieron obra y trayectoria de románticos y părnasianos -franceses sobre todo- partidarios incondicionales del Arte por el Arte?

Repitamos las palabras que hace 80 años dijera Chernishevsky: "El arte por el arte es una idea tan extravagante como la riqueza por la riqueza, la ciencia por la ciencia. Todos los asuntos deben servir al hombre si no quieren ser vana y ociosa ocupación; la riqueza existe para que la goce el hombre, la ciencia para ser guía del hombre; el arte debe servir, también para algủn provecho esencial y no ser un placer estéril". De placer estéril, efectivamente, es el destino que trae al mundo, como un pecado original, toda poesía que se fuga del hombre y su problema, rompe lanzas con el mandato de la Tierra y se ubica en aquel campo neutral entre el cielo y el infierno (Estuardo Núñez, ob. cit.) quemando las naves del retorno a los litorales humanos donde, bajo un signo inexorable, el espíritu del hombre se desangra y construye. $\mathrm{Y}$ ya es hora de proclamar que la poesía pura - como la música pura o la pintura purason quimeras y sólo quimeras, cuyo culto debe proscribirse para siempre. La poesía, el Arte en general, no puede escapar al deber ineludible que le asigna el mundo, al papel que justifica su existencia, a la tarea en que se resuelve su contribución al mejoramiento de la conciencia humana. El Arte no puede dejar su sombra, no puede saltar de su sombra, como en el proverbio árabe. El arte, como to dijo el alto espíritu de Tolstoy, es hecho por hombres y para los hombres, y si no, se convierte en algo estúpido y ridiculo, cuando no vitando.

Esta exhibición del purismo peruano, en cuanto a tendencia, no significa negarles aptitud poética a sus cultivadores. Discutible y rebatible su actitud, no lo es la aptitud poética, que en menor a mayor grado posean, aunque se esterilice -ya lo probamos- en su. fuga a las latitudés deshumanizadas del purismo.

No interesando un análisis de la producción purista, cierro este comentario, sólo a título de información, con una lista de los libros aparecidos hasta hoy: Martín Adán (La casa de cartón, novelapoema, 1928), C. Oquendo de Amat (5 metros de poemas, 1927). Enrique Peña Barrenechea (Cinema de los sentidos puros, 1931, Elegía de Bécquer y retorno a la sombra, 1935), Emilio Wesphalen 
(Insulas extrañas, 1933, Abolición de la muerte, 1935), Xavier Abril de Vivero (Dificil trabajo, 1935, Descubrimiento del alba, 1937).

\section{EL REGIONALISMO- POETICO}

Conviene, y mucho, decir algo sobre la realidad geográfica y étnica del Perú para evitar equívocos en la comprensión del regionalismo poético. Con frecuencia alarmante, comentadores limeños de nuestra literatura -que desconocen el pais o lo visitan en tren de turistas - hacen desde la capital generalizaciones arbitrarias y perniciosás que escamotean, sobre todo para la exportación, el verdadero panorama de esas realidades, de ligazón tan íntima con la realidad literaria.

Siete millones de habitantes pueblan el Perú. Según el más aproximado de los cálculos, esa población se descompone así:, 50\% "indios", $32 \%$ mestizos, $15 \%$ blancos, $3 \%$ para otros grupos (negros, zambos, "injertos"). Pero como lo dije ya -y mi expresión la corrobora Moisés Sáenz en su libro Sobre el indio peruano- "el Perú es un país de cholos" (Prólogo de El hondero de la laja encendida, Tercer cuaderno de poesía chola, Lima, 1939). El calificativo de "indios" con que se cataloga a tres millones y medio de peruanos, es muy convencional. Un indio puro, de existir en el Perú, lo sería racial, jamás espiritualmente. Ahí está si no el "nuevo indio" de Uriel García, con raíces leales a su ambiente, hijo irrenegable de su geografía, pero hispanizado por absorber, bajo el imperativo histórico, todo lo que dió la mano civilizadora, o desciviliżadora, de Occidente. E1 llamado indio peruano no es sino un mestizo en la primera etapa, que no apresura su proceso de acholamiento trabado por el tremendo drama de sus problemas insolubles, el de la Tierra particularmente. En consecuencia, la población mayoritaria del Perú es mestiza. El cholo es quien le da fisonomía a la nacionalidad, quien conjuga mejor su espiritu: El acholamiento es lo que impulsa, por otro lado, el problema de la peruanización, como lo dijo certeramente el mismo Sáenz, comentador imparcial de esa realidad: "el mestizaje corre paralelo con el desarrollo de la nacionalidad; es más: mestizaje y peruanización son, en cierto sentido, sinónimos". 
Afirmada esa realidad, observemos la ubicación de los pobladores en el mapa peruano. La Costa, en su extensión superficial de 180,000 kilómetros cuadrados, ocupada sólo en los valles, es residencia de casi todos los blancos y de los grupos negroides y asiáticos. Movida por factores económicos, convive allí una fuerte población mestizo-chola que aumenta año a año. La Sierra, con su vasto escenario de 450,000 kilómetros, es el escenario de los cholos. La Montaña -más propiamente, la selva- con 770,000 kilómetros casi inexplorados, es mestiza en sus $5 / 8$ partes, correspondiendo el resto a blancos inmigrantes y a las tribus salvajes que van incorporándose lentamente a la civilización.

Cuna y escenario de los cholos es la Sierra, ya lo dije. Los Andes presiden su peripecia biológica y social. Desde las cresterías nevadas -que galopan leguas en su avance longitudinal - se desgalga la brava realidad geológica, a resolverse en un violento océano de altiplanicies, desfiladeros, barrancos y mesetas. Aquel estupendo escenario conjuga toda una gama de panoramas y de climas. De río a cumbre se desovilla impávido el paisaje, remudando zoologías y floras, como en un desdoblamiento vertical de frutos y contrastes. De contrastes, he ahí el término exacto. $Y$ sobre esa Naturaleza contrastada, el contraste múltiple del hombre.

Hay una escala económica y social que va del pongo (servidor con vida y destino vendidos al patrón, que es el último escalón de la servidumbre y de la condición humana) hasta el gamonal -encomendero republicano- señor de tierras y de vidas, pasando por los pequeños propietarios, comerciantes, artesanos, comuneros y los Juanes sin Tierra. El mestizo sin heredad se resigna a la condición subalterna de alpartidario (trabaja la parcela enajenada para ir a medias en la cosecha), se emancipa como arrendatario de tierras en los latifundios, o emigra, con su aventura de peón, para alquilar el brazo a la explotación organizada de las minas o a someterse en los valles à la cadena del enganche (contrato vil con que se unce peones al desquite de una deuda que aumenta año a año, que a veces no termina de cancelarse en una vida y pasa en herencia a los hijos).

El contraste económico es igual al social; los dos se asemejan al cultural, que enfrenta minorías leídas al porcentaje desolador de mayorías analfabetas; $y$ los tres son iguales al contraste politico, que muestra hombres sin derecho para comandar su destino, que 
han olvidado hasta el "somos libres" del himno, frente a una oligarquia de caciques y mandones dueña de todas las formas de la economía y de la opresión. En cultura, en economía, en política, mayorías hambreadas. En todos los órdenes, mayorías hambrientas de reivindicaciones, lógicamente.

No insisto ahora en el tema. Volveré posteriormente a él, para evidenciar nuevos contrastes regionales del mestizo, que ayudan a comprender las particularidades de su mensaje literario.

En esa realidad -hojeada en síntesis - nace, evoluciona y se estructura la actitud con que aparece en la literatura peruana el regionalismo poético. Emerge de la Tierra, con todos los mandatos cósmicos del ámbito, trayendo la expresión inajenable del paisaje y la voz del hombre que allí cumple su dramático tránsito. Con el regionalismo llega el primer gran intento de lograr la peruanización total de la literatura y las provincias imponen la presencia lírica de un Perú inédito.

Dije que la insurgencia inicial del regionalismo poético se resolvió en mera actitud. $Y$ fué así, efectivamente. Los poetas se yerguen atơnitos, deslumbrados, indecisos. La sirena del modernismo canta aưn, bien que a la sordina, su postrera invitación a la lujuria musical y colorista. Los poetas empiezan por domarse a la violenta pasión de los paisajes. Luego captan el tránsito del hombre, como animación decorativa del paisaje. Por último, se plantan frente a el, en el primer paso decisivo, y empiezan la encendida contemplación de su drama. Pronto el propio hombre ha de estremecerse con la angustia đel grito inaugural.

Pero no adelantemos. Esa primera etapa del regionalismo poético correspondió a la simple actitud. Estando en vigencia aquella actitud surge el nombre equívoco con que se bautiza el movimiento: indigenismo. Indigenismo ¿ por qué? ¿Por sus elementos, por sus personajes, por su temario, por su raíz o por su fin? Alberto Ureta declara que la nueva poesia peruana es indigenista y no indigena, porque nace de la contemplación del indio, no del indio mismo. Innegable la afirmación en cuanto se refiere a la contemplación, pero niego categoría de veraz al nombre convencional con que se denomina, y siguen denominando algunas, al hombre del Ande. Mestizo irrefutable, cholo innegable, aunque conjugue diversos grados de acholamiento, el personaje de la poesía regionalista -autor 
y actor- no puede retroceder a los moldes biológicos y espirituales del incario, por el mero hecho de recibir la denominación de indio.

Otra cosa es afirmar -y con alto orgullo- que en nuestra sangre prevalece el mandato de la raza primitiva, la india, acentuando soberanamente sus cualidades superiores, en obediencia al dictado de las leyes étnicas. Pero ese mandato ya no sale al mundo en quechúa o aymará, sino en castellano; no moviliza el impulso particular de una raza, sino los impetus concertados de una mezcla de razas; no inspira el gesto parcial sino la actitud total; $y$ es ya un mandato superado de consonancias actuales con la vida, capaz de afirmar el triunfo de sus hombres, en el escenario de un nuevo mundo social.

La obra de aquel mandato no puede llamarse indigenista. Tampoco es indio el realizador de ese mandato. Mestizo el nuevo hombre, mestizo su fruto. Si cholo el poeta, cholas sus realizaciones. Es ab. surdo, entonces, mantener denominaciones en desacuerdo con la realidad. En el primer esfuerzo organizado para reivindicar la realidad mestiza de nuestra lírica, y para combatir el nombre equívoco que se dió a la poesía regionalista, publiqué en Buenos Aires La baraja del cholo (Editorial Indoamérica, 1935). De entonces a hoy, va cediendo terreno la terca actitud de los comentadores que persistían en hacer circular una denominación en abierta riña con la realidad. El regionalismo poético peruano - de la literatura peruana en general- es un movimiento mestizo, paralelo y afín con las jornadas nativistas de sus hermanos de Indoamérica, que confluirá en el abrazo de un Arte emancipado, para el cual se acuñó ya el nuevo nombre: mesticismo.

Desde el año 30 los poetas regionalistas se desprenden de sus posiciones contemplativas - la mera actitud que dijéramos- y avanzan en actitud restelta a identificarse con la problemática geográfica y humana. Ellos mismos - sujetos de poema y de drama - ensayan la explosión de su gran voz inédita. En distinta escala, digámoslo desde ahora, por determinación del disparejo mestizaje. Con su tónica regional, más propiamente. Lo que no atenta, sino completa. con sus recados vitales, el vigoroso mensaje por venir. 
EL SUR PERUANO

Guillermo Mercado es el poeta sureño de perfil lírico más elocuente. Desde la geografía luminosa y cordial de su Arequipa, alza la voz ancha, gozosa y optimista de Tremos (1933). Luego se identificará a la tragedia del cholo arequipeño, ya no eñ poesía, para darnos El donato (Relato, 1935).

De Mercado es este trozo que recoge la emoción andariega del arriero, personaje cuotidiano y típico de la Sierra peruana:

Veinte $\mathrm{y}$ tantas leguas de camino, arriero sudoroso, te traes encinchadas sin saberlo, a la cintura; también te traerás los paisajes que chocaron en tu pecho al doblar cuestas bravas, amigo. Cómo se ve que un frío cortante ha despellejado a tu voz que arreaba noche y día, y que el Sol arriero de pampas ha veniodo galopando en tus espaldas.

te has traído en los ojos la dureza de los cerros y en tu rostro quemado el beso gris de las distancias, un jirón de cielo alegre se envuelve en el pañuelo azul de tu cuello, $y$ aún se siente pasar por tus hombros la invisible caballería del viento,...

(De Tremos, "Perfil del arriero")

Alejandro Peralta luce otra expresión lírica y la rubrica sobre un mapa definido: la meseta. Nace estremecida por una pesadumbre desolada - función del paisaje-, pero grávida de vitalidad y trascendencia. Es un vasto río poético, poblado de altas voces plásticas, donde espejea como un azogue trágico el alma en protesta de los gentíos sojuzgados. Es en 1934 cuando su producción encuentra fisonomía cabal. Tal año - lo apunta alguien- "Peralta se trasforma de turista de su propio escenario en intérprete de aspiraciones humanas, en campeón de los desheredados". Se apagan las pupilas contempladoras del hombre que : 
...desde el amoratamiento de sus ojeras

destila sobre las quemadas mejillas de la tierra,

un llanto desvaído de acuarelas...

(El Ande, 19)

para que su antena capte las ondas de aquella reflexión donde agazapa su incendio la protesta:

...el yatiri metido en la balsa habla de hambrunas y pestes, de cómo día a día crecen en leguas los cercos...

y avanza a la comprensión del hombre alerta, que erguido en su paisaje y atento al mundo:

... .ya entiende que no sólo los indios mueren a miles, sino también los obreros y campesinos...

(El Kollao, 1935)

Una nueva revelación, una verdadera revelación, ha de ser el libro aquel que estructura, según sus propias palabras, "con tendencia al lenguaje popular" y que siendo expresión de su personal tragedia, "lo será también del pueblo a cuya raíz pertenece".

Con Altipampa (1933) y Tawantisuyo (1935) se alinea otra voz lírica del Sur. Más enérgica pero menos humana que la de Peralta; y menos lírica pero más dinámica que la de Mercado. Es la voz de Emilio Vásquez, quien eleva aquel canto:

...en tambor de gritos

se ha trocado mi pecho veterano...

y en el "Casamiento de la Santusa", echa a circular este acorde, metáfora a grito, de puro sabor a tierra y pueblo:

... todos juegan la cinta morada de sus sueños

Wiphala

wiphalita

hooo!

(Altipampa) 
y conjuga el amor y el ambiente en la escala lírica de este bello poema

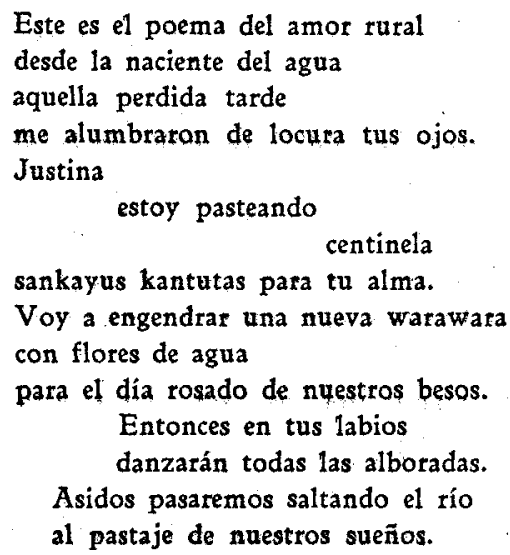

$$
\text { ("Imilla", Altipampa) }
$$

De Kollasuyo, reciente edición, es este verso por donde define ya su entrada al propio corazón, a la oscura tragedia, de su gente:

Gentes de la poblada

tiradas coma fardos en las calles

mascando la misma $\mathrm{Nada}$

la misma angustia de tantos dias sin pan.

Oídos a esa admonición de campanas

y a ese imposible del aire de combate.

Tantos hombres hambrientos

con las manos crispadas

alimentados con sólo hostilidades

de hambre, de frío y de no hacer nada.

Abur abur

Adelante sin volver la mirada

hay que germinar otro mundo para vivir.

Los hombres quieren incinerar las penas

en los osarios del dolor humano

$y$ açabar con esta novela de dolor sin fin.

("Yaravi", Kollasuyo, 1940. Edit. Antena) 
Con menos impulso lírico pero con más emoción aparece $M$. Gallegos Sanz (El flechero satírico, Arequipa, 1932; Caima, 1933) y se evidencia la evolución de Alberto Cuentas del romántico $R u$ mores del Titicaca (1929) al Desde la cumbre (1934), expresión más neta del paisaje sureño. Junto a ellos completan este cuadro voces no muy bien definidas pero en marcha a su verdadera expresión regionalista: Alberto Paz de Novoa, Luis de Rodrigo, Carlos Dante Nava, Alberto Mostajo, Federico Agüero, Pedro Arenas. Los juegos florales del Cuzco (1929) revelaron a un poeta cuzqueño de ancho camino: Luis Nieto, autor del "Romance cholo a Garcilaso de la Vega", que comentaré en un próximo trabajo dedicado a los poetas nuevos.

La tierra, con su mandato sensual en carne viva, no ha tenido mejor intẻrprete que Emilio Armaza (Falo, 1928), de producción lastimosamente silenciada posteriormente. A él le debimos hace poco la reactualización del nombre de un poeta arequipeño de la pasada generación, quien sólo en posible competencia con Santos Chocano y Domingo Martínez Luján, se alza como el más experto manipulador de la técnica lirica: Renato Morales.

Recordando a los desaparecidos, no es posible olvidar a Alberto Guillén, que con la agilidad de su inquieto espiritu tornó a la región en sus años postreros. La muerte arrebató la culminación de una obra que maduraba bajo los soles mestizos de Arequipa y de la que son muestras elocuentes Cancionero (1934) y su inconcluso Arequepay. Sólo uno de los primeros soldados del nuevo movimiento poético y rotundo captador de las emociones sociales, pudo escribir aquella bella "Elegia a un soldadito muerto en una revolución sudamericana", cuya parte final dice:

Has muerto. ¿Sabes? ¡Has muerto! $\mathrm{Y}$ sin hacet aspavientos;

sin decir 7 palabras, sin Magdalenas, sin Marías, y estás aquí sin esperanza de un Tercer Día.

Has muerto, eso es todo. ¿Has muerto sin pot qué, en nombre de qué?

¿Para redimir a quién, soldadito, carpinterito?

(Publicado en Digesto Latinoamericano, México, '1936) 
Repetiré aquí por necesario y exacto lo que afirmé sobre la fisonomía lírica del Sur-peruano, en el prólogo del Hondero de la laja encendida (Lima, 1939): "Se advierten de inmediato las características de los poetas del Sur: una modulación casi primitiva por su fresca sugerencia; giros y metáforas inusitadas para el mecanismo occidental del castellano; el amago constante pero certero de voces quechuas y aymarás en el verso. Lo cual está lejos de ser cualidad negativa, y menos afán de descastellanizarnos, tal cual lo dice la cándida alharaca de los escribidores castizos. La razón es sencilla y lógica: nadie ignora que en el Sur alternan mano a mano quechua, aymará y castellano. Y no me extraña que el quechua, dialecto flexible y dulce, desplace al castellano en todos los menesteres de la intimidad, y se haga presente en las expresiones más significativas de la efusión lírica. Antero Peralta explica lógicamente ese fenómeno, al decir : así como el poliglota alemán acomoda inconscientemente los diferentes idiomas que habla a la sintaxis de la lengua germana, así, de la misma manera, el escritor acomoda el castellano a los resortes mecánicos de la estructura gramatical y lógica del quechua o del aymará"; y "como hay palabras, giros y figuras literarias, en las lenguas nativas, sin equivalente castellano, no hay más remedio que consignarlas...".

A lo expuesto agregaremos una característica más: la poesía sureña oscila entre un audaz dominio del hombre sobre la naturaleza (Emilio Vásquez, Guillermo Mercado) y la casi omnipotencia del paisaje sobre el hombre (Alejandro Peralta, en su primera etapa; Cuentas, Paz de Noboa, etc.)

\section{EL CENTRO PERUANO}

La poesía representativa del Centro peruano muestra una tonalidad más emancipada del paisaje. No en lo que implica aliento cósmico o emoción telúrica, sino en lo que de cantera para hallazgos plásticos y objetivos tiene el paisaje. En esta poesía el hombre parece hablar con una voz de inflexiones metálicas, pero candente y premiosa, como si lengua y garganta barajaran metales encendidos. El paisaje es sólo un trasfondo para el vuelo enérgico, desnudo, categórico de las metáforas, que nacen a rayar gritos calientes en un aire acuchillado de protestas, ennegrecido de rencores y fatigas 
por el aliento de una muchedumbre de pulmones alquilados. Leales a su sino - su sino de poetas y de hombres- no evaden la novela amarga de la peonada minera, uncida al horizonte negro de los boquerones, de vida entumida y desollada, angustiándose en el presagio de los finales súbitos a manos de la muerte o del time-check, cuando la invalidez devuelve su drama a los caminos, donde yerguen su vigencia perspectivas sin esperanza y sin pan.

Con estos poetas toma forma y se evidencia la irrupción reivindicadora del mestizo. Esa poesía es la traductora inicial de la protesta social del cholo. Las voces cardinales corresponden a Serafín del Mar y a Magda Portal. Del Mar da la primera nota de la épica social en Radiogramas del Pacífico (1927), superada en El hombre de estos años (1929). Hacia 1934, se juntan las voces afines del Perú y dan a luz Cantos de la Revolución Serafín del Mar, Alberto Hidalgo, Ciro Alegría, Magda Portal, Juan José Lora, Gerardo Barrios, Aurelio Martínez y Julián Petrovick.

Con una humanidad sin contorsiones, pura, elemental, desnuda, habla Serafín a la mujer y compañera:

Y entre mis brazos floreó tu nombre moreno, ruralista compañera,

que cuelgas en el jardin de tu alegría

el letrero de esta palabra hecha fe: revolución.

Sin variar impulso y acento Del Mar se enfrenta a la ciudad y al panorama proletario de las fábricas:

\author{
Las chimeneas de la urbe \\ proveedoras de la guerra, \\ te saludan con himnos de humo; \\ y los hombres estremecidos de las fábricas, \\ te regaton con sangre \\ para que nazca la libertad, \\ desde tus raíces profundas.
}

Como él, Magda Portal crea y expande una poesía encendida y altiva. Su Esperanza y el mar tiene el aliento de los temas eternos y universales - el amor, la muerte, la sed de creación. Después, 
adapta el hondo acento humano de la voz primeriza al cauce ancho y enérgico que exige el mensaje social. Así se le admira en "Canto proletario", "Dos poemas a los compañeros de Vitarte" y "Han muerto ya".

Dentro de esa tónica levantada y ejemplar disuena la voz de José Varallanos, liquidando realidad y futuro del cholo en "El hombre del Ande que asesinó su esperanza"; y queda sin ubicación el "Wayno" turista de Luis F. Xammar, en el cual baila' un mestizo convencional muy semejante al que caza la kodak impasible de los gringos.

Sería injusto omiti la cita de uno de los poetas de más alerta inquietud $\mathrm{y}$ más aleccionadora limpieza en vida y obra: Clodoaldo Alberto Espinoza Bravo. Vigente la vanguardia, fué uno de los que esgrimió con más soltura y técnica el mecanismo revolucionario del verso. La poesía lo ha perdido, pero to ha ganado el ensayo, para volverlo a la escena literaria con los mismos atributos ejemplares del poeta. Voluntariamente retraído en su Jauja natal, vive atento a nuestro latido y al latido espiritual de todas las latitudes, ajeno a las concupiscencias de la política criolla y evadido de agachadas y canonjías. Alguna vez le exhibiré de frente y de perfil, en esa su gran actitud excepcional, pero común en la dramática trayectoria de todos los artistas libres del Perú.

\section{EL PERU-NORTE}

$Y$ he aquí el Norte con la insurgencia de la poesía más equilibrada y definida, dentro de nuestro regionalismo poético. Un equilibrio vigoroso concierta el mandato de la tierra, la voz del paisaje, el grito del hombre. Una definición rotunda, derivada del parejo mestizaje, sustenta y canaliza la creación de los poetas. La expresión lírica traspone la etapa inicial del balbuceo y supera aquel trance angustioso de los creadores iniciales resuelto en la explosión tajante, primitiva, áspera de los vocablos, nacidos sólo a sugerir o a clavar violentas referencias para la comprensión del lírico mapa que gobiernan. Es ya la poesía que fluye y no estalla; no deletrea sino lee; precisa y no alude; no elude sino enfrenta; y, segura de su pulso, licencia los fogoneos sin destino y moviliza' su suerte en una parábola directa, buscando el corazón de los impactos. 
Su arranque, sus perfiles, su psicología hay que explicarlos, llanamente, con las realidades geográficas y étnicas de la región. La Sierra del Norte no tiene la brusca y violenta geología de los Andes sureños. Les contrapone, más bien, cadenas de montañas bajas y ágiles. Su geografía es luminosa y bravía, pero no hay en sus Andes la violencia cósmica capaz de agobiar, como en el Sur, a hombres y paisajes. La melancolia esteparia del Kollao "que sustenta el fondo instintivo de sus gentes" - según habla Uriel García- no tiene significación ni vigencia en parte alguna en esta Sierra, huérfana de mesetas y volcanes. Es el remanso cordillerano, si es posible la expresión, pero que exhibe -ausentes altiplanicies y cráteres- ese muestrario de flores, de faunas y contrastes, común a la Sierra peruana, que se inicia en la realidad cálida $y$ fluvial de los temples y desenvuelve facetas ascendentes hasta el cresterío nevado de las cumbres.

Es en este mapa donde el mestizaje peruano exhibe su vanguardia. La presencia del cholo cabal, parejo, diríamos, no es aquí un suceso parcial, sino una realidad total. De La Libertad a Piura, el Norte serrano está poblado por gentes mestizas en la sangre, el habla, la economía, el espíritu y hasta en la vestimenta y las canciones. El quechua y los dialectos han sido eliminados definitivamente. El cholo es peón, aparcero, pequeño propietario o arrendatario, aunque subsistan, sólo en Piura, comunidades convencionales. Ha desaparecido la bella expresión india de licllas, anacos y monteras. Reina la paja de los sombreros de junco, de palma y jipijapa; la tela mestiza de driles y percales, casinetes y manfores. Los pollerones de lana disparan un solo color neto y violento; los ponchos apagaron su acuarela soleada y sólo admiten el gobierno de una gama de "nogales". Las antaras triunfan sobre las quenas. La guitarra y el acordeón traducen la voz del sentimiento, que en veces se aviene al dondoneo cálido del arpa, pero no utiliza ni conoce la desembocadura de granizada del charango. En cambio la caja (instrumento indio) mantiene en pie, y. obedecido, su contragolpe resonante; pero el soplo que moviliza la melodía de su flauta dirige maricholas y serranitas, en vez de waynos, chuscadas, cachasparis y reiphalas.

En El Tunante, don Abelardo Gamarra (nacido en Huamachuco, Departamento de La Libertad), hay que reconocer el ante- 
cedente más remoto en que sustenta el Norte -acaso todo el Perú- su tradición regionalista. En Cien años de vida perdularia - su último libro - nace a la prosa la primera visión literaria costumbrista de la Sierra mestiza, junto a la fustigación más despiadada con que se han castigado vicios y defectos republicanos. La inquietud precursora del gran huamachuquino la heredan, y la superan también, José Eulogio Garrido en la prosa (piurano) y en el verso César Abraham Vallejo (nacido en Santiago de Chuco). Garrido, en quien vive un poeta, un soberbio poeta suplantado por el prosador, es el más calificado realizador de interpretaciones literarias andinas. Lo prueba el luminoso panteísmo de sus estampas del Ande, trabajadas en un ejercicio concertado de poeta y de filósofo, en que identifica fervorosa y resueltamente a la tierra y al hombre. Vallejo, ya se dijo, voltea en el atisbo primerizo de lo nuestro y desdobla la novedad lírica de su propia tierra natal en el pregón de "Los heraldos negros". No me refiero a Enrique López Albújar - por su condición de piurano costeño-, a quien le debemos, no obstante, el más documentado análisis de la psicología india. Pero sí vale destacar la pura y alta figura de José Gálvez, impagable alentador de los esfuerzos literarios en busca de la entraña nuestra y erigido en el más limpio ejemplo de intelectual austero y de hombre libre. $\mathrm{Y}$ registratemos, también, el aporte de Pedro Barrantes Castro (Cumbrera del mundo, relato cholo).

Cuando el estridentismo remontaba el vuelo a su más aguda cima se revela desde la revista Sierra una voz de ancha promisión: la de Anaximandro Vega (nacido en Chota, Cajamarca). Toda la primera promoción lírica regionalista paga tributo al hallazgo deslumbrador de su ámbito. Pronto, sin embargo, se sacude el deslumbramiento inicial, $y$ antes de hundir las manos en la greda encendida, donde tierra y hombre hacen palpitar sus mandatos para el verso, vocea su proclama a los vientos:

Clarín de raza;

cien mañanas

como cien banderas libres

surgirán a tu voz en la cumbre más alta

en esta noche de siglos. 
Clarín de raza;

descenderá tu grito sobre nuestras ciudades cubistas

las teñirás de rojo $\mathrm{y}$ apagarás la voz del mar.

(Fragmento de "Cquera")

No bastarán al espíritu invocación y paisaje. Hay que fijar al hombre, avanzar hacia él y vaciarle las entrañas del drama para sacar al sol la gusanera recóndita. Aquí está el peón serrano, retornando de su trasplante al remoto valle costeño. Para recibirlo

...el tambor de puro alegre

se descuplga por las quebradas

desde su casa que bate carcajadas...

Por la vuelta del Pancho

la casa está que revienta.

Las mujetes en el baile

se desgajan las caderas zumbadoras,

y. la chicha hierve entusiasmos.

pero el peón ya no está, no puede estar, igual a cuando partió:

Sus ojos miran de lejos

con un mirar de arena...

Ya no podrá espantar la realidad que le acosa; volvió enditado y ha de retornar a desquitar la deuda. Y si muere - la infamia es conocida - la deuda pasará en herencia a los hijos. Por eso entre la fiesta

mira dentro hacia la sombra...

$Y$ ya en los ojos huraños de Juancito

descubrió su misma pena...

Pero será el bandolero personaje de aquel poema perdurable con que el bandido impávido de las serranías, entra por primera vez a 
trazar su estela legendaria, poblada de tiros y romances, en la literatura peruana:

Aurora de alcohol incendiada a tiros

$$
\text { -hoguera crepitante- }
$$

ponche caliente de cuidados

tras una cierra puertas en desolación.

Porque este hombre que trae al brazo los caminos como un poncho de listas

ha bebido la sangre de todos los crepúsculos

ha herido de luz todas las noches

y ha quebrado vidas de hombres como ramas

si le han estorbado en su sendero.

Hoy bajo su mirada tosca y honda

se aplastan las casas del poblado

igual que cuando están al pie de un cerro.

Pero él reventará sus alegrías

y se irá después

$$
\text { ' como se va el río. }
$$

Estrujará los vientos con su caballo para abrazar el alma de la montaña.

Derramará por las quebradas

su robusta canción de plomo y pólvora.

$Y$ luego en las pampas

-donde quiera-

se dormirá bajo el cielo

con su mujer más fiel: su carabina.

El sabe que algún día

-no le importa-

le dejarán como un huanchaco

con el pecho rojo a puñaladas

y en sus labios muerto el sol.

Después en su camisa como en un mapa

buscarán el ritmo de su vida.

("El bandolero y su poema")

Soslayado en veces, apenas aludido en "panoramas" y "resúmenes" que fragua la mano jesuíta de los "críticos", está presente aquí para dejarlo librado al juicio imparcial de los lectores. Completando su fisonomía lírica doy fragmentos de su reciente poema "Relieve de ño Tomás y su canto", cabal captación de los cantores 
típicos, cuya personalidad no es posible desglosar del libro romântico de nuestros pueblos:

-Viejo gallo de aldea

que aventaba cholas entre los maizales

todos los caminos conocieron sus pasos.

-Alli viene ño Tomás...

A las mujeres les trepaban las caderas a los ojos

y las copas se entreabrian esperándolo.

Apuraba el café negro de todas las noches, exprimía la leche de la última estrella y dejaba siempre encinta su guitarra de una nueva canción.

Siempre se le verá detrás de las trancas en un llegar sin llegada,

con su risa redonda, su gesto voluntarioso

y su guitarra que tenía un nombre de mujer.

Ciro Alegría (nacido en Cajabamba), destacado desde su aparición como poeta, cumple sus primeras jornadas líricas adscrito resueltamente al regionalismo poético. Pronto la emoción social ahonda sus reclamos y su propia acción beligerante condensa en la lírica revolucionaria que saca a luz en Cantos de la revolución, en unión de otros poetas (ob. cit.) Desterrado a Chile, violenta su vocación de auténtico poeta, truncándola definitivamente. Pero para gloria de la literatura peruana, y continental, se revela el macizo novelista que acaba de consagrarse ampliamente con El mundo es ancho y ajeno.

$\mathrm{Y}$ aquí me veo enfrentado a comentar un hecho: el año 1935 edité en Buenos Aires La baraja del cholo. En condición de autor me inhibo de hacer valoración alguna, pero no puedo eludir la constatación siguiente: aquel libro significó la primera vuelta de ojos hacia el cholo - llamándole así- y es el primer esfuerzo organizado para su reivindicación lírica. Hasta entonces se aludió esporádicamente al mestizo - desde El Tunante- y persistía el nombre de indio para llamar al peruano de los Andes, y su consecuente de indigenista para todo cultivador de la literatura regional. 
Esa mi actitud, afirmada en Poemas del meridiano cholo y El hondero de la laja encendida, es producto diáfano y director de mi orgullosa suerte de mestizo. Y a ella me enraiza el mandato ineludible de mi sangre y de mi tierra. No podrán torcerla - silenciarla si- quienes, escamoteando verdades a su propia conciencia, escamotean la realidad literaria peruana hasta en los libros de texto.

Con el solo propósito de mostrar todas las faces de la lírica regionalista, pongo a continuación muestras de mi obra :

Me encontrarás en la palabra de los niños,

con el sol de los pobres,

por la pasión del pueblo dispuesta en las tonadas,

en los días que acaban sin uná mano abierta.

Me hallarás al ordenat el quehacer de tus sueños,

con los brazos que luchan merecer sus descansos;

cuando alargues un pan:

y también a la hora en que los hombres preguntan sus derechos

y contestan escribiéndole al pecho

el último deber las carabinas.

Aqui no hay paso al llanto.

Sabes bien dónde hallarme: en lo limpio, en lo libre:

y alli, con los de abajo.

Canta mi paso firme, dirigido al destierro!

("Recado al filo del destierro")

Esta es la voz de que hablo:

los paisajes la terciaron al hombro

igual que al aguacero, $y$ al sol.

Desde los seis caminos de amor de las guitarras

sus mujeres la llevan encinchada a las ancas.

Yo la recuerdo en el silbo de los que pisan barro, derrotada por los niños con hambre.

en mi primer palabra.

Es una voz que ha latido descalza

desde que vino al mundo,

que se lee la vida en un alfabeto de sudores,

trae la Tierra en Brazos, y la goza con rabia

como a mujer ajena.

Esta es la voz de que hablo.

Es una voz más ancha que el pecho de su mapa,

donde madura el salto.

agachada, como un puma resuelto.

("Anuncios del mensaje mestizo") 
No cerraré este articulo sin antes citar, y en cita emocionada, a un poeta y maestro norteño eliminado por la muerte: Cristóbal Meza. Voz lírica de la más clara esperanza, Meza mantuvo su vida en el cauce de una rebeldía honrada e imbatible: explicación amarga pero orgullosa de su pobreza, de su injusto olvido y de su propio fin.

Con producción no definida en este movimiento o silenciada antes de su definición, alineo los nombres de Luis Valle Goycochea, efectivo poeta que se desplaza en aquel planeta tierno de las vivencias infantiles, consonantado con el discurrir cuotidiano de la emoción poblana (Canciones del Rinono y Papagil, 1932; El sábado y la casa, 1932; La elegía tremenda y otros poemas, 1937) ; N. Chávez Aliaga (Parábolas del Ande, 1928) y Fidel Zárate (Los Huiros, 1933).

Los juegos florales universitarios (1940) dieron paso a la revelación lírica de Julio Garrido - primer puesto- quien ha recogido su producción primigenia en dos libros recientes, y va camino de una decidida entonación regionalista, lo mismo que Jacobo Florián, que está venciendo sus peligrosas incursiones al negativo $p u$ rismo, para enfilar por nuestra ruta; y Mario Puga, que acusa un firme tono social en Cuatro poemas civiles. Felipe Arias Larreta (Poemas, Trujillo, 1940), manipulando el romance, capta la emoción lugareña de su tierra natal, pero no toca aún la cuerda reivindicadora del mestizo. Un estudio posterior me permitirá exhibir plenamente esta nueva promoción lírica.

\section{AUSENCIA DE COSTA Y SELVA}

De inmediato se advertirá que todos los poetas citados, como representativos del regionalismo poético, pertenecen a la Sierra peruana. Se me podría objetar, por ello, que su representación no abarca al Perú entero. Me adelanto a la objeción para declarar que la poesía regionalista revisada es la expresión del mestizo de los Andes, o sea el único tipo racial definido en nuestro pueblo. Su definición racial le brinda, lógicamente, la posesión de su espiritu, de una personalidad, de una voz, capaces de erigirlo en auténtico portavoz de la expresión nacional: 
De esta suerte se contrapone al habitante híbrido de la Costa, al que va dominando, además, porque a la manera de la civilización incaica, el acholamiento desciende de los Andes en un avance incontenible de absorción, para borrar a la población criolla, impersonal y blandengue, y crear nuevos tipos humanos en cuya fisonomía triunfan los perfiles inconfundibles del cholo.

Frente a la total realidad mestiza del Ande se levantan la Costa-zamba, la Costa-injerta, la Costa-criolla, la Costa-blanca. Y hay una población de nativos costeños -descendientes de las pasadas civilizaciones del litoral- y, también, el nuevo núcleo formado por las inmigraciones mestizas de la Sierra.

La expresión zamba ha encontrado su mejor conjugación literaria en Enrique López Albújar (Poemas afro-yungas-Matalaché: novela), Angela Ramos (poetisa), los cuentistas José Díez Canseco, Ricardo Alcalde y H. Falconí Sevilla. Como Fernando Ortiz en Cuba -aparte su condición de magnífico cuentista-, Fernando Romero es el estudioso más calificado de la personalidad de color en el folklore costeño del Perú.

La voz lírica de la población nativa y de los nuevos núcleos cholos, acampados en los valles, no encuentra aún poeta capaz de conjugarla. Hay alguien que va en camino, sí Nicanor de la Fuente (nacido en Pacasmayo), quien, cancelando su etapa vanguardista, ha tomado ruta por las comarcas de la emoción popular ( La feria de los romances). En prosa habían dado ya la nota fiel de esa realidad José Mejía Baca (Aspectos criollos), Paredes y León Barandiarán ( $A$ golpe de arpa).

El romancero criollo de José Torres de Vidaurre es el único aporte poético valedero, en la traducción de las modalidades criollas -atisbadas por Ricardo Palma, Juan de Arona, Ascencio Segura-, pero circunscrita a Lima y sin identificación alguna con los dramas humanos del litoral.

La Costa-injerta (producto del cruce asiático) insinúa apenas su presencia - su primera presencia- con José Ferrando (Panorama hacia el alba, novela de próxima publicación y ganadora en el Perú del Concurso Latinoamericano de novelas).

El futuro dará a luz la voz o las voces de una Costa con unidad étnica - cuando el mestizaje cruce y recruce la mixtura de razas 
desparramadas en sus paralelos-, cuya expresión lírica para salvarse y perdurar tendrá que transponer la simple anécdota y encarar la traducción honrada de su medio social, geográfico y humano.

La Selva, por otro lado, no ha dado aún su forjador lírico, aunque por los caminos del cuento la hagan presente Fernando Romero, Manuel Beingolea y J. C. Chirif.

Cuando se habla de la expresión de un pueblo - y de cualquiera expresión: politica, económica, social, étnica - se sobrentiende que la referencia abarca a las mayorías nacionales. $\mathrm{Ni}$ el negro o sus derivados, ni el injerto, ni el inmigrante acriollado, pueden pretender la representación lírica peruana. Por faltarles definición racial, las latitudes costeñas carecen de personalidad, de espíritu. Espíritu y personalidad de afirmación creciente, en cambio, puede exhibir en todos los órdenes aquel habitante mayoritario del Perí: el cholo. (Tal afirmación no niega la existencia de modos literarios propios de cada minoría ni desconoce el aporte brindado, más que todo al folklore costeño, por la realidad mulata y zamba, particularmente, contribución tan magníficamente estudiada por Fernando Romero).

El triunfo continental de Ciro Alegria es la confirmación más rotunda de la potencialidad literaria del cholo, y demuestra la existencia de una cantera capaz de abastecer la producción de un arte de auténtica raíz peruana. Los críticos conservadores y los literatos de salón están confundidos con el triunfo de un cholo y con la consagración de una obra chola (Alegría y El mundo es ancho y ajeno). Hace pocos años, cuando nuestros poemas regionalistas proclamaban los derechos líricos del cholo, los clanes literarios limeños sonrieron despectivamente ante la insurgencia de este capítulo de la literatura chola. Algunos fueron más allá; negaron capacidad de supervivencia al nuevo movimiento, creyendo - desconocedores de su propia patria - que el cholo era exponente de una minoría, y de una minoría "inferior", sin posibilidades de convertirse en autora y personaje de su propio arte. Baste la sola cita de Alegría - triunfador desterrado-, ante quien ahora todos empiezan a inclinarse, como ante "el sol que nace" de la política criolla, para reafirmar todo lo dicho en relación al cholo, como tipo representativo peruano en la vida $y$ en el Arte. 
Cancelando las vigencias de una órbita lírica, el Perú salta a los caminos revolucionarios buscando apasionadamente una nueva expresión. La vanguardia que insurge por obra de ese afán ahoga el imperio de tódos los ismos precedentes y se adelanta al encuentro de una poesía desnuda, enemiga de lo formal, negadora de la rima, salida del verso, resuelta en un vasto ejercicio de metáforas. Pronto remansa la insurgencia y se dan las señales para encauzar las nuevas conquistas. El escenario postvanguardista advierte, entonces, el arribo paralelo de dos tendencias : el regionalismo y el purismo, realidades positiva y negativa del actual orden poético peruano.

En el panorama actual de la literatura peruana el regionalismo juega un papel de rango excepcional: ser el gonfalonero de un arrollador movimiento de peruanización. En el campo lírico representa la reivindicación y afirmación del mestizo. La poesía purista, y la neutral -a la que dedicaré estudio aparte-, representan la realidad negativa, de posición indefendible, aprovechable sólo para poner de relieve los perfiles y contrastar el mensaje de la poesía regional, mensaje posible de sintetizar así: vuelta de ojos al ámbito propio, inajenable; conjugación de las pasiones humanas y las aspiraciones reivindicadoras del mestizo; poesía humana, y por humana, de emoción social. Espíritu nuevo sobre todo. Mensaje que conjuga el recado lírico de cada región, la tónica regional de una poesía, en cuyas diarias afirmaciones madura la definición de su realidad futura.

Su intrasferible función de poesía representativa del Perú -portavoz de las mayorias nacionales, traductora lírica del mestizo, reivindicadora del paisaje peruano- significa la imposición definida de la voz regional en la literatura peruana y la conducción de su destino monopolizada por el centralismo capitalino desde el Coloniaje. $\mathrm{E} l$ purismo puede decirse que es, en realidad, el último reducto del gobierno literario del Perú por élites de la capital y representa a aquella Lima conservadora y feudal, llamada con razón el antiPerú, distinta y hasta opuesta a la Lima liberal y perdurable que dió y sigue dando soberbios exponentes en todos los órdenes del pensamiento. 
$\mathrm{Y}$ en última afirmación, el regionalismo poético es sólo un capítulo del vasto movimiento con que se desplaza al futuro el Arte de nuestro pueblo, guiado por una fe firme y voluntariosa.

Abraham Arias-Larreta,

Lima, Perú. 
